\title{
Projeto de acolhimento e humanização para acompanhantes: a inserção do serviço social e da enfermagem de uma instituição federal do Rio de Janeiro
}

\author{
Erika Fonseca Camargo Marsico, M.Sc.*, Sandra Batista da Silva**
}

${ }^{*}$ Enfermeira, Hospital Universitário Clementino Fraga Filho/ UFRJ, **Assistente Social do Hospital Universitário Clementino Fraga Filho/UFRJ

\begin{abstract}
Resumo
O presente trabalho descreve a prática do Assistente social e da Enfermeira no atendimento a familiares e acompanhantes de pacientes internados em um Hospital Federal Universitário no Rio de Janeiro, utilizando como ferramenta metodológica uma reuniáo semanal realizada com esses acompanhantes do serviço de internaçôes clínicas. Essa atuaçấo é fundamentada no Programa Nacional de Humanização do Ministério da Saúde, nos Códigos de Ética Profissional do Assistente Social e do Enfermeiro e na discussão de temas emergentes do cotidiano do processo de hospitalizaçáo. Considerando que o assistente social e o enfermeiro são os profissionais que se apresentam como os principais elos de ligação entre paciente, família e instituição de saúde, este trabalho teve como objetivos desenvolver atividades com orientaçóes e educação em saúde, baseando-se no tripé que norteia a instituição: Ensino - Pesquisa - Assistência. Os resultados obtidos foram: diminuição de queixas a ouvidoria; maior número de acompanhantes orientados sobre direitos e deveres e sobre a composição da equipe multiprofissional; melhor controle da quantidade de pertences e alimentos nas enfermarias trazidos pelos acompanhantes, aumento de doadores de sangue e redução dos conflitos existentes entre família e equipe.
\end{abstract}

Palavras-chave: Serviço Social, Enfermagem, acolhimento, humanização da assistência.

\section{Abstract \\ Project of humanization and receptiveness to companions: the insertion of social work and nursing of a federal institution in Rio de Janeiro}

This work describes the practice of social work assistant and nurse in assisting family and companions of inpatients at a University Federal Hospital in Rio de Janeiro, using as methodological tool a weekly meeting with the companions of inpatient clinic service. This acting is based on The Brazilian Ministry of Health's Program for Humanization, on the social worker and nurse Code of Professional Ethics and daily debates that emerge from the hospitalization process. Considering that the social worker and nurse are the main links between patient, family and health institution, the objective of this work was to 
develop activities with guidance and education on health, following the tripod: education, research and caring. The results are: reduction in claims, higher number of companions well informed about rights and duties, multiprofessional staff, better control of belongings and food brought by the companions to the Nursing ward, increase of blood donators and reduction of conflicts between family and hospital team.

Key-words: social work, nursing, user embracement, humanization of assistance.

\section{Resumen}

\section{Proyecto de acogimiento y de humanización para los acompañantes: la inserción del Servicio Social y de Enfermería de una institución federal de Río de Janeiro}

Este trabajo describe la práctica del asistente de servicios sociales y del enfermero en la atención a familiares y acompañantes de los pacientes hospitalizados en un hospital federal universitario en Río de Janeiro, utilizando como herramienta metodológica una reunión semanal realizada con eses acompañantes del servicio de hospitalización. Esta actuación se basa en el Programa Nacional de Humanización del Ministerio de la Salud, en el Código de Ética Profesional del asistente social y del enfermero y en los debates de temas emergentes en el cotidiano del proceso de hospitalización. Considerando que el asistente social y el enfermero son los profesionales que se presentan como los principales contactos entre el paciente, la familia y la institución de la salud, este trabajo tuvo como objetivo desarrollar actividades con orientaciones y educación en salud, basado en el siguiente trípode: Enseñanza - Investigación - Asistencia. Los resultados obtenidos fueron: reducción de quejas; un número más grande de acompańantes orientados sobre derechos y deberes; mejor control de cantidad de pertenencias y alimentos en las enfermerías, aumento de donantes de sangre y reducción de conflictos entre la familia y el equipo.

Palabras-clave: Servicio Social, Enfermería, acogimiento, humanización de la atención.

\section{Introdução}

Quando falamos, atualmente, em qualidade de serviços ou produto, podemos definir como sendo "um conjunto de propriedades de um serviço (produto) que o tornam adequado à missão de uma organização (empresa) concebida como resposta às necessidades e legitimas expectativas de seus clientes" [1]. Quando nos referimos à qualidade dos serviços de saúde, temos como um dos principais indicadores a qualidade da assistência de enfermagem, levando-se em consideração que é com a equipe de enfermagem que o cliente hospitalizado e seus familiares mantêm o maior vínculo, devido à continuidade dos cuidados nas 24 horas.

Assim, para a equipe de enfermagem atuar dentro de um sistema de gestáo de qualidade, ela precisa estar capacitada para assegurar que seus procedimentos estejam em conformidade com as necessidades dos clientes, indo ao encontro das suas demandas e aumentando seu grau de satisfação. Uma das ferramentas preconizadas pelo Ministério da Saúde como integrante do processo de melhoria da qualidade dos serviços de saúde é o acolhimento, definido como uma ação tecno-assistencial que pressupóe a mudança da relação profissional/usuário e sua rede social através de parâmetros técnicos, éticos, humanitários e de solidariedade, reconhecendo o usuário como sujeito e participante ativo no processo de produção da saúde [2].

Dentro desse contexto, o acolhimento é considerado um requisito fundamental para a promoção da melhoria da qualidade da assistência de enfermagem ao cliente hospitalizado, assim como também aos seus familiares. Ter sensibilidade para a escuta e o diálogo, mantendo relaçóes éticas e solidárias entre os profissionais e os pacientes/familiares, envolve um aprendizado contínuo e vivencial, pouco enfatizado no ambiente de trabalho, levando-se em conta, ainda, o predomínio de estruturas administrativas tradicionais, rígidas e burocratizadas. Deve ser enfatizada, também, a dificuldade nesse processo de acolhimento, pela sobrecarga de trabalho, pelo dimensionamento inadequado dos profissionais de enfermagem e pelas condiçóes inapropriadas de trabalho, o que acarreta uma rotina mecanizada, visando apenas o cumprimento de tarefas e 
distanciando, cada vez mais, a relação profissional / paciente/ familiar, no que se refere aos aspectos bio-psico-socio-espirituais [3].

O processo de hospitalização é acompanhado, muitas vezes, de imposiçóes de normas e rotinas institucionais para os pacientes, como horários rígidos para banho, refeiçôes e visitas, além da perda de sua privacidade, das perdas afetivas, sociais e de suas atividades de lazer, retirando a pessoa de seus hábitos e deixando de lado suas características pessoais, gerando sentimentos de medo, angústia e solidão.

A presença e participação dos familiares no processo de internação confortam e tranqüilizam o paciente, diante de tantas rupturas e de pessoas "estranhas", minimizando a distância de casa e das notícias, além de permitir que o paciente se sinta mais protegido, dentro de um ambiente estranho, principalmente, quando se trata de idosos ou crianças. A interação da família, também, com a equipe de saúde possibilita um enriquecimento dos dados sobre o paciente e, conseqüentemente, melhor resultado para ele e maior retorno profissional [4].

De acordo com a Política Nacional de Humanização [5], acompanhante é o "representante da rede social da pessoa internada que a acompanha durante toda sua permanência nos ambientes de assistência à saúde". A sua inserção no processo de internação é de suma importância para captar melhor os dados do contexto de vida do doente e ajudar na identificação das suas necessidades, para incluí-lo nos cuidados com a pessoa doente, para permitir a integração das mudanças provocadas pelo motivo da internação e para fortalecer a confiança da pessoa internada.

O Ministério da Saúde [6] propóe como alguns dos parâmetros de adesão à Política Nacional de Humanização na Atenção Hospitalar a existência de grupos de trabalho de humanização, a garantia de visita aberta, por meio da presença do acompanhante e de sua rede social, respeitando a dinâmica de cada unidade hospitalar e as peculiaridades das necessidades do acompanhante, mecanismos de recepçáo com acolhimento aos usuários e mecanismos de escuta para a população e os trabalhadores.

Contudo, como chefe de enfermagem de um dos setores pertencentes ao Serviço de Internaçóes Clínicas de um Hospital Universitário da rede federal localizado na cidade do Rio de Janeiro e como uma das Assistentes Sociais responsáveis por esse Serviço, percebemos que os objetivos que buscamos com a presença dos familiares, durante a internação não serão plenamente atingidos, se a equipe multiprofissional não realizar um trabalho de orientação, educaçáo e envolvimento dos familiares nesse processo. Além disso, um dos itens preconizados relacionados à atenção ao cliente, respectivamente, no Manual Brasileiro de Acreditação Hospitalar do Ministério da Saúde/Organização Nacional de Acreditação [7] é a humanização da atenção ao cliente/paciente e a existência de um mecanismo de orientação aos pacientes e familiares. Essas questôes precisam ser trabalhadas, pois lidamos com familiares e acompanhantes de várias classes sociais, com diferentes níveis de instrução, cultura, religião, hábitos e costumes os quais, muitas vezes, podem interferir no processo de recuperação do paciente, no que se refere, por exemplo, ao desconhecimento de seus direitos e deveres, da realidade hospitalar, da composiçáo dos membros da equipe de saúde e sobre controle de infecção hospitalar.

A partir dessas situaçóes detectadas e vivenciadas no dia-dia nas Unidades de Internações Clínicas e considerando que o Assistente Social e o Enfermeiro são os profissionais que se apresentam como os principais elos de ligação entre paciente, família e instituição de saúde, foi iniciado um trabalho com a chefia de enfermagem e o Serviço Social responsável por este setor. A proposta de assistência é atuar junto aos acompanhantes e familiares dos pacientes hospitalizados, em relaçáo à carência de esclarecimentos acerca da hospitalização. Surgiu da necessidade de sistematizar informaçóes relacionadas à dinâmica hospitalar, à composição da equipe multiprofissional e às medidas básicas de prevenção de infecção hospitalar.

Inicialmente, o contato da equipe interdisciplinar com os acompanhantes ocorria durante a intervenção direta ao paciente na enfermaria. A chefia de enfermagem e o serviço social identificaram a necessidade de um espaço, onde essas orientaçóes fossem abordadas com maior acolhimento, o que desencadeou a formação de uma atuação profissional interdisciplinar de caráter educativo, informativo e humanizado.

Esse trabalho baseia-se na relevância da participaçáo dos familiares no processo saúde, doença e tratamento do paciente e possui como objetivos desenvolver atividades com orientaçóes e educação em saúde, baseando-se no tripé que norteia a instituição: Ensino - Pesquisa- Assistência. Sendo assim, pretendemos com a sua divulgaçáo contribuir para otimizar a qualidade da assistência aos pacientes 
internados e seus familiares, reduzir o estresse emocional gerado durante a internação e fortalecer as iniciativas de humanizaçáo existentes na rede hospitalar pública.

Desse modo, o objetivo do presente estudo é apresentar como vem sendo aplicadas as diretrizes da Política Nacional de Humanização, no que se refere à valorização das relações interpessoais entre pacientes, familiares e profissionais de saúde, a partir da experiência vivenciada pela Enfermagem e pelo Serviço Social, num hospital universitário do Rio de Janeiro. As reunióes desenvolvidas junto com os acompanhantes possuem os seguintes objetivos específicos:

- Debater a questão do que é ser acompanhante;

- Abrir espaço para escuta, orientação e reflexão;

- Possibilitar a discussão das questóes trazidas pelo grupo;

- Esclarecer direitos e deveres do acompanhante na instituição;

- Melhorar a interaçáo acompanhante/equipe multidisciplinar, visando o conforto do paciente e acompanhante, durante sua permanência na instituição;

- Fortalecer o tratamento do paciente, estimulando a participação ativa da família;

- Propiciar educação em saúde na instituição;

- Socializar as informaçóes, aumentando o compromisso dos acompanhantes e o nível de conscientizaçáo;

- Integrar todos os setores no processo de assistência humanizada aos pacientes e acompanhantes.

\section{Material e métodos}

Trata-se de um relato de experiência do trabalho que vem sendo realizado, baseado na Política Nacional de Humanização iniciado pela Enfermagem e o Serviço Social junto aos acompanhantes dos pacientes internados no $9^{\circ}$ andar de um hospital universitário do Rio de Janeiro. Este andar, atualmente, é dividido em três postos, onde ficam localizadas as enfermarias pertencentes ao Serviço de Internações Clínicas da instituição. Além disso, um desses postos do andar é destinado às especialidades médicas como transplante de fígado, medula, rins e pulmão e cirurgias plásticas e interna pacientes do SUS e de convênios de saúde da rede privada.

O trabalho é desenvolvido através de reunióes semanais, com duração prevista de uma hora, com grupo de acompanhantes dos pacientes internados nessas enfermarias com a participação direta da Chefia de Enfermagem, Serviço Social, Chefia da Equipe Médica e Comissão de Controle de Infecção Hospitalar. Os acompanhantes são convidados, pessoalmente, pela equipe de enfermagem e pela assistente social responsável a participarem da reunião, que se inicia aproximadamente às $10 \mathrm{~h} 30 \mathrm{~min}$. O espaço físico destinado à atividade é a Sala de Humanização do $9^{\circ}$ andar, por estar próxima às enfermarias, ser arejada, contar com boa iluminação e pela possibilidade de dispor as cadeiras em círculo, visando à interação e o conforto dos participantes.

Os encontros são registrados em livro ata. A dinâmica ocorre através de sugestôes da equipe e dos próprios acompanhantes para uma melhor abordagem, no sentido de educá-los e orientá-los, quanto às normas e rotinas da instituiçáo, tendo como base a educação em saúde. A reunião inicia-se com a distribuição de cartilhas do acompanhante elaborada pela instituição, grupos de discussão, orientaçóes sobre infecção hospitalar e demais questóes sugeridas.

Todas as demandas apresentadas são colocadas em discussão e, na medida do possível, tenta-se dar resolutividade, encaminhando ao setor e/ou profissional competente. Utilizam-se recursos audiovisuais como álbuns seriados, cartazes, filmes, dinâmicas de grupo e exercícios de relaxamento com o objetivo de promover também a saúde mental de quem cuida, pois se considera que quem cuida também precisa de cuidados e atenção.

\section{Resultados}

Os resultados obtidos, até então, com as reuniôes são:

- Diminuição de queixas a ouvidoria;

- Maior número de acompanhantes orientados sobre direitos e deveres;

- Maior controle da infecção por transmissóes cruzadas e contato;

- Aumento de doadores de sangue;

- Redução dos conflitos existentes entre família e equipe.

As avaliaçóes desse projeto são realizadas a partir de observações, visitas às enfermarias e reunióes entre o Serviço Social e a Chefia de Enfermagem, no intuito de buscar soluçóes para as demandas postas, em prol de um bom atendimento da equipe multidisciplinar. Tendo em vista os resultados iniciais positivos com a implantação do projeto, 
tem-se ainda como metas integrar todos os andares de internação no processo de acolhimento e humanização aos acompanhantes de pacientes internados na instituição e desenvolver um trabalho semelhante voltado diretamente aos profissionais que cuidam desses pacientes, nas 24 horas (enfermeiros, auxiliares e técnicos de enfermagem).

\section{iscussão}

Considerando as características sociais e culturais específicas de cada pessoa, há qualidades e atitudes que o profissional espera encontrar no familiar acompanhante e há aquelas as quais este familiar espera encontrar na equipe de enfermagem. Quando essas expectativas se coadunam, ocorre uma relação de reciprocidade, participação e solidariedade, favorecendo uma relação de cuidado [8]. Sendo assim, é preciso pensar em vários aspectos relacionados ao acolhimento desse acompanhante, no contexto da internação como, por exemplo, de que forma podem ser contornadas as carências no ambiente físico hospitalar, não preparado para abrigar adequadamente mais uma pessoa, num espaço em que, muitas vezes, não é adequado nem para os clientes?

Além da adequaçáo do espaço físico para o acompanhante, torna-se necessário que o processo transformador também esteja calcado nas relaçóes humanas, tendo como base o comprometimento com os princípios norteadores das políticas de humanização dos espaços institucionais, favorecendo, assim, que familiares/acompanhantes e profissionais de saúde tornem-se parceiros nesse processo.

\section{Conclusão}

A experiência desse trabalho demonstra a importância da prática educativa e acolhedora no processo saúde/doença, da Enfermagem e do Serviço Social. A prática educativa contribui para a mudança, ampliação e percepção da população usuária dos serviços oferecidos. O Serviço Social e a Enfermagem atuam com base na garantia dos direitos básicos de cidadania, participação social, democracia, justiça social, eqüidade e humanização.

Levando os usuários à reflexão e ao entendimento do que é ser acompanhante, objetivamos a humanização do atendimento e um melhor relacionamento entre acompanhante e equipe de saúde. A humanização depende da mudança das pessoas, da ênfase em valores ligados ao relacionamento entre usuários dos serviços e profissionais de saúde e na possibilidade de transformar o trabalho em processo criativo e prazeroso.

A reforma da atenção, no sentido de facilitar a construção de vínculos entre equipes e usuários, é um instrumento que tem se mostrado poderoso para mudança. Na realidade, a construçáo de organizaçóes que estimulem os operadores a considerar que lidam com outras pessoas, durante todo o tempo, e que estas pessoas como eles próprios têm interesses e desejos com os quais se deve compor é um caminho forte para se construir um novo modo de convivência.

\section{Referências}

1. Mezomo JC. Gestão da qualidade na Saúde. Princípios básicos. São Paulo: Manole; 2001.301p.

2. Brasil. Ministério da Saúde. Política Nacional de Humanização. Acolhimento com avaliação e classificação de risco: um paradigma ético-estético no fazer em saúde. Série B. textos básicos de saúde. Brasília: MS; 2004.

3. Casate JC, Correa AK. Humanização do atendimento em saúde: conhecimento veiculado na literatura brasileira de enfermagem. Rev Latinoam Enfermagem 2005; 13(1):105-11

4. Amin TCC. O paciente internado no hospital, a família e a equipe de saúde: redução de sofrimentos desnecessários [dissertação]. Rio de Janeiro: Escola Nacional de Saúde Pública/ Fundação Oswaldo Cruz; 2001.

5. Ministério da Saúde. Política Nacional de Humanização. Visita aberta e direito à acompanhante. Série B. Textos básicos de saúde. Brasília: MS; 2004.

6. Ministério da Saúde. HumanizaSUS. Política Nacional de Humanização. A Humanização como eixo norteador das práticas de atenção e gestão em todas as instâncias do SUS. Série B. Textos básicos de saúde. Brasília: MS; 2004

7. Ministério da Saúde. Manual de Acreditação das Organizaçóes Prestadoras de Serviços Hospitalares. Brasília: MS; 2006.

8. Squassante ND. A dialética das relaçóes entre a equipe de enfermagem e familiares acompanhantes no hospital: implicaçôes para o cuidado de enfermagem [dissertação]. Rio de Janeiro: Escola de Enfermagem Anna Nery/ Universidade Federal do Rio de Janeiro; 2007. 